\title{
Selective hydrogenation of acetylene on graphene- supported non-noble metal single-atom catalysts
}

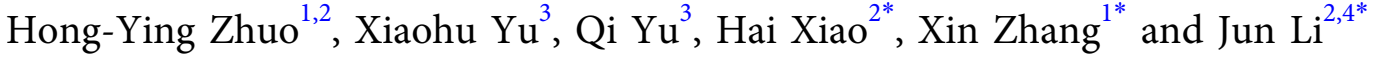

\begin{abstract}
Large-scale production of polyethylene in industry requires efficient elimination of the trace amount of acetylene impurity. Currently, zeolite adsorption or the conversion of acetylene to ethylene via selective semi-hydrogenation on Pd catalysts is the commonly used method. In this work, we investigate the reaction mechanisms of acetylene hydrogenation on defective graphene (DG) supported singleatom catalysts (SACs), $\mathrm{M}_{1} / \mathrm{SV}-\mathrm{G}$ and $\mathrm{M}_{1} / \mathrm{DV}-\mathrm{G}(\mathrm{M}=\mathrm{Ni}$, $\mathrm{Pd}$ and $\mathrm{Pt}$ ) using density functional theory (DFT), where SV-G and DV-G represent DG with single and double vacancies, respectively. It is shown that the metal single-atoms (SAs) as well as their different coordination numbers both affect the activity and selectivity of the hydrogenation process. $M_{1} / D V-G$ provides better $\mathrm{H}_{2}$ dissociation ability than $M_{1} / S V-G$, which accounts for the poor acetylene hydrogenation activity of $M_{1} /$ $S V-G$. Based on the reaction barriers, $\mathrm{Pt}_{1} / \mathrm{DV}-\mathrm{G}$ and $\mathrm{Ni}_{1} / \mathrm{DV}-\mathrm{G}$ are better catalysts than other systems considered here, with $\mathrm{Ni}_{1} / \mathrm{DV}-\mathrm{G}$ exhibiting high selectivity for the semi-hydrogenation product of acetylene. These results provide insights for the design of highly selective and noble-metal-free SACs for acetylene hydrogenation on carbon materials.
\end{abstract}

Keywords: graphene, single-atom catalysts, acetylene hydrogenation, density functional theory

\section{INTRODUCTION}

Selective semi-hydrogenation of acetylene to ethylene is an important industrial process for large-scale production of polyethylene, because a trace amount of acetylene will compromise the polymerization of ethylene [1,2]. In this regard, highly optimized catalysts are required to convert carbon-carbon triple bonds efficiently and selectively to carbon-carbon double bonds without full hydrogenation to ethane. Palladium-based materials are the commonly used catalysts, but Pd surfaces are usually passivated to prevent full hydrogenation into alkane in an ethylene-rich atmosphere due to the presence of subsurface hydrogen species [3-5], which are very reactive but less selective than surface $H$ atoms [6-11]. It has been reported that the formation of subsurface $\mathrm{H}$ strongly depends on the size of Pd particles, and smaller particles form less subsurface $\mathrm{H}$ atoms [12-14]. Therefore, decreasing the size of Pd particles may be an effective way to mitigate full hydrogenation.

In the past several years, considerable attention has been paid to single-atom catalysts (SACs), which minimize the size to the extremum and yet exhibit appealing catalytic abilities [15-24]. Kyriakou and co-workers [25] reported that the atomically isolated $\mathrm{Pd}\left(\mathrm{Pd}_{1}\right)$ atoms alloyed in the less reactive $\mathrm{Cu}(111)$ surface can substantially enhance the $\mathrm{H}_{2}$ dissociation and display high selectivity in the hydrogenation process of acetylene. Other metal supports also have been found to have high acetylene conversion and high ethylene selectivity, such as $\mathrm{Pd}_{1}-\mathrm{Au}$ [26], $\mathrm{Pd}_{1}-\mathrm{Ag}$ [27-29], $\mathrm{Pd}_{1}-\mathrm{Zn}$ [30] and $\mathrm{Pd}_{1}$-In [31] bimetallic systems. In addition, single-atom $\mathrm{Pd}_{1}$ supported on mesoporous polymeric graphitic carbon nitride (mpg$\mathrm{C}_{3} \mathrm{~N}_{4}$ ) also showed a higher activity and product selectivity for the hydrogenation of alkynes and nitroarenes, compared with the corresponding benchmark catalysts based on nanoparticles [32]. The prepared $\mathrm{Pd}_{1} / \mathrm{C}_{3} \mathrm{~N}_{4}$ catalysts also exhibited high coking resistance [33]. It is suggested that the design of $\mathrm{Pd}_{1}$ active site changes the adsorption mode of ethylene from the strongly $\sigma$-bonding on Pd surface to the weakly $\pi$-bonding on SACs, which suppresses further hydrogenation of ethylene. Therefore,

\footnotetext{
${ }^{1}$ State Key Laboratory of Heavy Oil Processing, College of Chemical Engineering, China University of Petroleum, Beijing 102249, China

${ }^{2}$ Department of Chemistry and Key Laboratory of Organic Optoelectronics \& Molecular Engineering of Ministry of Education, Tsinghua University, Beijing 100084, China

${ }^{3}$ Shaanxi Key Laboratory of Catalysis, Shaanxi University of Technology, Hanzhong 723000, China

${ }^{4}$ Department of Chemistry, Southern University of Science and Technology, Shenzhen 518055, China

* Corresponding authors (emails: haixiao@tsinghua.edu.cn (Xiao H); zhangxin@cup.edu.cn (Zhang X); junli@tsinghua.edu.cn (Li J))
} 
the design of singly dispersed $\mathrm{Pd}_{1}$ atoms is a viable strategy for improving the reaction activity and selectivity of acetylene semi-hydrogenation.

It has also been found that the existence of subsurface carbon can increase the selectivity of acetylene semihydrogenation toward ethylene on Pd surfaces [6-8,3436]. The dissolved carbon atoms in the top layers of $\mathrm{Pd}$ surface are likely to modify the surface electronic structures of Pd, which apparently favors partial hydrogenation. Moreover, the formed subsurface Pd-C phase can exclude the adsorbed hydrogen $\left(\mathrm{H}^{*}\right)$ from populating the subsurface regions and hence prevent the complete hydrogenation of alkyne [6]. Thus, the selective hydrogenation reaction catalyzed by the $\mathrm{Pd}_{1}$ atom supported on carbon materials is worth to be investigated. Indeed, graphene-supported $\mathrm{Pd}_{1}$ catalysts are reported to exhibit remarkable hydrogenation selectivity and durability in 1,3-butadiene hydrogenation and acetylene hydrogenation reactions $[37,38]$. However, the exact structure of active site and the catalytic reaction mechanism underlying its high activity and selectivity remain unclear.

Here we investigated the hydrogenation mechanism of acetylene on the graphene-supported $\mathrm{Pd}_{1} \mathrm{SAC}$, to provide new insights into the understanding of its structurefunctionality relationship. Density functional theory (DFT) calculations were carried out to systematically investigate the geometric and electronic structures of $\mathrm{Pd}_{1} /$ graphene catalyst, as well as its activity and selectivity for acetylene hydrogenation. Single-vacancy graphene (SV$\mathrm{G})$ and double-vacancy graphene (DV-G) are compared to understand the support effect, and the difference between the typical group VIII noble metal (Pd and $\mathrm{Pt}$ ) and the non-noble metal (Ni) as SACs is also investigated.

\section{THEORETICAL AND COMPUTATIONAL DETAILS}

All of the theoretical calculations were performed using periodic DFT with the Vienna $a b$ initio simulation package (VASP5.3.2) [39,40]. Spin-polarized Kohn-Sham calculations were carried out by using the generalized gradient approximation with the Perdew-Burke-Ernzerhof (PBE) exchange-correlation functional [41]. The projector augmented-wave (PAW) potentials with scalar relativistic effects were used for taking into account the interaction between the valence electrons and ionic core with the nucleus. The valence electrons were designated by $3 d^{8} 4 s^{2}$ for $\mathrm{Ni}, 4 d^{9} 5 s^{1}$ for Pd, $5 d^{9} 6 s^{1}$ for Pt, $2 s^{2} 2 p^{2}$ for C, and $1 \mathrm{~s}^{1}$ for $\mathrm{H}$, respectively. An energy cutoff of $400 \mathrm{eV}$ was used for the plane wave expansion. The geometries were optimized with the self-consistent field and force convergence criteria set to $10^{-5} \mathrm{eV}$ and $0.02 \mathrm{eV} \AA^{-1}$, respectively. Brillouin zone (BZ) integration was sampled over a $3 \times 3 \times 1$ Monkhorst-Pack (MP) $k$-point grid. No atoms were geometrically fixed during all our calculations. Bader charge analysis was used to evaluate the electron transfer [42]. The charge density differences were obtained using the formula of $\Delta \rho=\rho_{\mathrm{A}+\mathrm{B}}-\rho_{\mathrm{A}}-\rho_{\mathrm{B}}$, where $\rho_{\mathrm{X}}$ $(\mathrm{X}=\mathrm{A}, \mathrm{B}$ or $\mathrm{A}+\mathrm{B})$ is the electron density of $\mathrm{X}$. The minimum-energy pathway for elementary reaction steps was located using the climbing image nudged elastic band (CI-NEB) method [43-45]. Vibrational analysis was further conducted to confirm the transition states with only one imaginary frequency.

A hexagonal supercell $(6 \times 6$ graphene unit cells) of pristine graphene containing 72 atoms was introduced to model the graphene supports and a vacuum layer of $15 \AA$ along the $z$ direction was placed between the graphene sheet and its mirror images to avoid the artificial interactions among them. One or two carbon atoms of pristine graphene support were removed to form anchoring sites of the models for defective graphene (DG), which were defined as SV-G and DV-G, respectively. We chose these two kinds of DG because they have been proved to be better substrates than pristine graphene for anchoring the single metal atoms $[46,47]$. The schematic diagram of the construction of $\mathrm{M}_{1} / \mathrm{SV}-\mathrm{G}$ and $\mathrm{M}_{1} / \mathrm{DV}-\mathrm{G}\left(\mathrm{M}_{1}=\mathrm{Ni}, \mathrm{Pd}\right.$ and Pt) models are shown in Fig. 1.

The binding energy $\left(E_{\text {bind }}\right)$ between the single metal atom and DG support is defined as $E_{\mathrm{bind}}=E_{\mathrm{M}}+E_{\mathrm{DG}}-E_{\mathrm{M}_{1} / \mathrm{DG}}$, where $E_{\mathrm{M}}, E_{\mathrm{DG}}$ and $E_{\mathrm{M}_{1} \mathrm{DG}}$ are the calculated energies of the single-atom metal, the DG support, and the $\mathrm{M}_{1} / \mathrm{DG}$ catalyst, respectively. According to this definition, the higher value of binding energy represents the higher stability of single atoms. The chemisorption energies

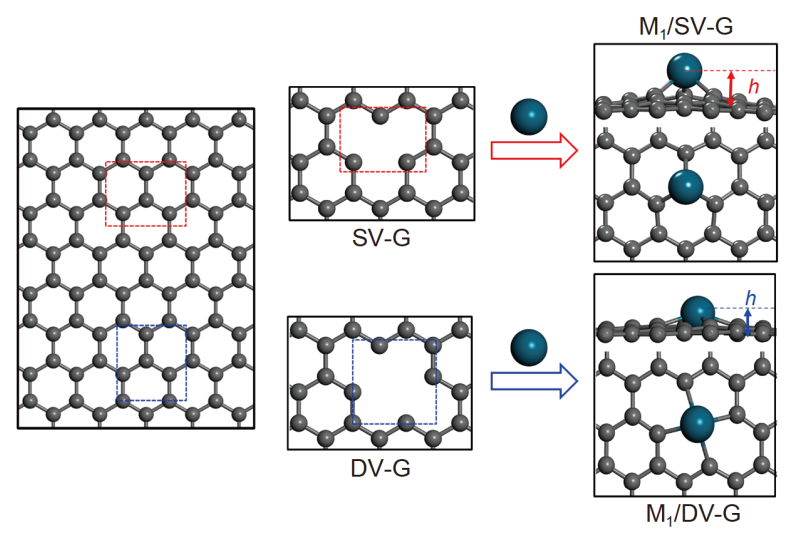

Figure 1 Schematic diagram of the construction of $M_{1} / S V-G$ and $M_{1} /$ DV-G $\left(\mathrm{M}_{1}=\mathrm{Ni}\right.$, Pd and Pt) models. 
( $E_{\text {ads }}$ ) of gas molecules on the $\mathrm{M}_{1} / \mathrm{DG}$ surface were evaluated by the equation of $E_{\mathrm{ads}}=E_{\mathrm{gas}+\mathrm{M}_{1} / \mathrm{DG}}-E_{\mathrm{M}_{\mathrm{l}} \mathrm{DG}}-E_{\mathrm{gas}}$, where $E_{\text {gas }+\mathrm{M}_{1} / \mathrm{DG}}$ and $E_{\text {gas }}$ are the total energies of the $\mathrm{M}_{1} /$ DG catalysts with the adsorbed gas molecules and the gas molecules respectively.

\section{RESULTS AND DISCUSSION}

\section{Geometric and electronic structures}

Previous theoretical investigations have shown that the metal single-atoms (SAs) prefer to be trapped at the vacancy site on DG as dopants [47-53]. Our findings are consistent with the previous results. For SV-G substrate, the dopant metal SAs bind with the three undercoordinated $\mathrm{C}$ atoms at the vacancy and protrude upward from the graphene surface (as shown in Fig. 1 and Table 1). The bond lengths of the three metal-carbon $\left(\mathrm{M}-\mathrm{C}_{\mathrm{G}}, \mathrm{M}=\mathrm{Ni}, \mathrm{Pd}\right.$ and $\left.\mathrm{Pt}\right)$ bonds are equal, indicating a local $C_{3 v}$ symmetry. Binding energies (Table 1) of $\mathrm{Ni}_{1} /$ SV-G, $\mathrm{Pd}_{1} / \mathrm{SV}-\mathrm{G}$ and $\mathrm{Pt}_{1} / \mathrm{SV}-\mathrm{G}$ are 6.96, 5.23 and $7.23 \mathrm{eV}$, respectively, in agreement with the literatures $[47,49,54,55]$. These energies are much higher than the adsorption energies of the corresponding SAs on pristine graphene surface, where metal atoms tend to form metal clusters due to weak binding with graphene $[49,56]$. For DV-G supports, the $\mathrm{Ni}_{1}, \mathrm{Pd}_{1}$ and $\mathrm{Pt}_{1}$ atoms also sit at the middle position of the di-vacancy and form four $\mathrm{M}-\mathrm{C}_{\mathrm{G}}$ bonds with the neighboring under-coordinated carbon atoms around the vacancy. The metal atoms are slightly elevated from the graphene plane, and the height is much lower than that on SV-G. Especially, the metal SA is almost embedded in the graphene surface for $\mathrm{Ni}_{1} / \mathrm{DV}-\mathrm{G}$ likely because of the small size of $\mathrm{Ni}$ atom. The calculated binding energies of SAs on DV-G are slightly smaller than those on SV-G, due to the structure deformation of optimized DV-G (Fig. S1). We also calculated the cohesive energy for the bulk form of each metal. The cohesive energies are 6.58, 3.71, and $5.53 \mathrm{eV}$ for $\mathrm{Ni}, \mathrm{Pd}$, and $\mathrm{Pt}$, respectively, which indicates that these metal SAs could be stable on the abovementioned DG surfaces.

According to Bader charge analysis (Table 1), metal SAs trapped on DG are positively charged, which are consistent with the charge density difference plots (Fig. S2), where significant charge transfer can be seen between metal SAs and their associated C atoms. The presence of increased charge densities in the region between the SA and the surrounding $\mathrm{C}$ atom indicates strong covalent metal-support interaction (CMSI) between them. In order to gain more insight into the electronic structures of $M_{1}$ / SV-G and $M_{1} / D V-G(M=N i, P d$ and Pt $)$, the density of states (DOS) plots were also plotted, as presented in Fig. $\mathrm{S} 3$. We can see the significant overlap between the $\mathrm{M} \mathrm{d}$ orbitals and C 2 p orbitals in all cases. All these changes in the electronic structures indicate the strong metal-support interaction between metal SA and the DG support. Therefore, the metal SAs are stable on SV-G and DV-G surfaces under ambient condition.

We also performed calculations on the corresponding SACs supported on double-layer graphene (G-DL), defined as $\mathrm{M}_{1} / \mathrm{SV}-\mathrm{G}-\mathrm{DL}$ and $\mathrm{M}_{1} / \mathrm{DV}-\mathrm{G}-\mathrm{DL}$, as shown in Fig. S4. It is found that the metal SAs form similar structures with those on the single-layer graphene. No obvious differences on the binding energies, geometric and electronic parameters (Table S1) are found compared with the results of the corresponding single-layer graphene model. Especially, the Bader charges of metal SA on G-DL model are almost the same with those on the singlelayer graphene model. As most of the published theoretical investigations on graphene-supported SACs utilized the single-layer graphene model [57-60], we only use the single-layer graphene model in this work. Moreover, our GGA calculations predict the Ni, Pd and Pt doping in DG favors closed shell systems with zero spin moment.

\section{Adsorption of gas molecules}

For semi-hydrogenation of acetylene to ethylene, strong adsorption of $\mathrm{H}_{2}$ and $\mathrm{C}_{2} \mathrm{H}_{2}$ and the facile activation of $\mathrm{H}_{2}$

Table 1 Binding energies $\left(E_{\text {bind }}\right)$, metal-carbon distances $\left(R_{\mathrm{M}-\mathrm{CG}}\right)$, heights $(h)$ of the metal atoms, Bader charges $\left(q_{(\mathrm{M})}\right)$ of $\mathrm{M}_{1} / \mathrm{SV}-\mathrm{G}$ and $\mathrm{M}_{1} / \mathrm{DV}-\mathrm{G}$ $(\mathrm{M}=\mathrm{Ni}, \mathrm{Pd}$ and $\mathrm{Pt})$

\begin{tabular}{|c|c|c|c|c|c|c|}
\hline & \multicolumn{3}{|c|}{ SV-G } & \multicolumn{3}{|c|}{ DV-G } \\
\hline & $\mathrm{Ni}$ & $\mathrm{Pd}$ & $\mathrm{Pt}$ & $\mathrm{Ni}$ & $\mathrm{Pd}$ & $\mathrm{Pt}$ \\
\hline$E_{\text {bind }}(\mathrm{eV})$ & 6.96 & 5.23 & 7.23 & 6.22 & 4.09 & 6.90 \\
\hline$R_{\mathrm{M}-\mathrm{CG}}(\AA)$ & 1.80 & 1.95 & 1.94 & 1.87 & 2.04 & 1.99 \\
\hline$h(\AA)$ & 1.43 & 1.81 & 1.87 & 0.26 & 0.98 & 1.22 \\
\hline$q_{(\mathrm{M})}(e)$ & 0.71 & 0.52 & 0.51 & 0.84 & 0.54 & 0.73 \\
\hline
\end{tabular}


and weak adsorption of $\mathrm{C}_{2} \mathrm{H}_{4}$ hold the key for the selective hydrogenation step. Therefore, the adsorption of the reactants and products are the important factors to be considered.

\section{$\mathrm{C}_{2} \mathrm{H}_{x}(x=2,4,6)$ adsorption}

In order to obtain the most stable adsorption configurations of $\mathrm{C}_{2} \mathrm{H}_{x}(x=2,4,6)$ on different surfaces $\left(\mathrm{M}_{1} / \mathrm{SV}-\mathrm{G}\right.$ and $\mathrm{M}_{1} / \mathrm{DV}-\mathrm{G}(\mathrm{M}=\mathrm{Ni}, \mathrm{Pd}$ and $\left.\mathrm{Pt})\right)$, several adsorption modes were considered. For $\mathrm{C}_{2} \mathrm{H}_{2}$ and $\mathrm{C}_{2} \mathrm{H}_{4}$ adsorption, metal SAs form metal-carbon bonding ( $\mathrm{M}-\mathrm{C}, \mathrm{M}=\mathrm{Ni}, \mathrm{Pd}$ and $\mathrm{Pt}$ ) with the two carbon atoms of $\mathrm{C}_{2} \mathrm{H}_{2}$ and $\mathrm{C}_{2} \mathrm{H}_{4}$, with the $\pi$ adsorption mode. This adsorption pattern is different from that on the corresponding metal surfaces, where the favorable adsorption of $\mathrm{C}_{2} \mathrm{H}_{2}$ is at the hollow site and $\mathrm{C}_{2} \mathrm{H}_{4}$ is bonded in a di- $\sigma$ adsorption mode $[8,61,62]$. For $\mathrm{C}_{2} \mathrm{H}_{6}$, the saturated molecule is hardly adsorbed on the surface except through weak van der Waals interaction. Generally, the adsorption strengths of $\mathrm{C}_{2} \mathrm{H}_{x}$ species change in the order of $\mathrm{C}_{2} \mathrm{H}_{2}>\mathrm{C}_{2} \mathrm{H}_{4}>\mathrm{C}_{2} \mathrm{H}_{6}$ (Table S2).

\section{$\mathrm{H}_{2}$ adsorption and dissociation}

The adsorption and activation of $\mathrm{H}_{2}$ are key steps in the hydrogenation reactions, which influence the activity and selectivity. For traditional selective hydrogenation catalysts, like Pd-based materials, $\mathrm{H}_{2}$ can be easily dissociated, and the formed hydrides on metal surfaces/nanoparticles can incorporate into the interstitial sites and form the less selective subsurface hydride [6]. Therefore, controlling the amount of hydrogen (coverage) near the reaction intermediate is an efficient way to avoid the complete hydrogenation. While for SACs, especially those with inert supports, the activation of molecular $\mathrm{H}_{2}$ is often heterolytic, different from that on traditional metal catalysts. How easy is the dissociation of molecular $\mathrm{H}_{2}$ is one of the critical steps for the hydrogenation reaction on SACs [63].

Four different adsorption types, including one molecular adsorption and three dissociative adsorption types (shown in Fig. S5), are calculated on each surface. On $\mathrm{Ni}_{1} /$ SV-G and $\mathrm{Pd}_{1} / \mathrm{SV}-\mathrm{G}$ surfaces, the $\mathrm{H}_{2}$ molecular adsorption states, with negative $E_{\text {ads }}$ (Table 2), are more favorable than the dissociative adsorption states, where the $E_{\text {ads }}$ are positive. On the $\mathrm{Pt}_{1} / \mathrm{SV}-\mathrm{G}$ surface, $\mathrm{HH}-1$ mode has the most stable structure, where the two dissociated $\mathrm{H}$ atoms both adsorbed on the $\mathrm{Pt}_{1}$, with an $E_{\text {ads }}$ of $-0.34 \mathrm{eV}$. This is similar to the theoretical results on the trinuclear metal clusters $\left(\mathrm{M}_{3}, \mathrm{M}=\mathrm{Ni}, \mathrm{Pd}, \mathrm{Pt}\right)[64]$ and the (111) surfaces of $\mathrm{Ni}, \mathrm{Pd}$, and $\mathrm{Pt}$ [65], where $\mathrm{H}_{2}$ is most easily dissociated on Pt. This trend may be attributed to the relativistic effects [64], which usually cause the $5 \mathrm{~d}$-metals to be off the trend from $3 \mathrm{~d}-$ to $4 \mathrm{~d}$-metals, and the $\mathrm{M}-\mathrm{H}$ bond strength, as it has been reported that the $\mathrm{M}-\mathrm{H}$ bond dissociation energies follow the sequence $\mathrm{Pd}<\mathrm{Ni}<\mathrm{Pt}[66,67]$.

On all $M_{1} / D V-G$ surfaces, $\mathrm{HH}-3$ mode has the most stable configuration, where the dissociated $\mathrm{H}$ atoms adsorb on the carbon atoms nearby the central metal atom, with relatively negative $E_{\text {ads }}$. Compared with other adsorption structures, the $\mathrm{HH}-3$ adsorption mode results in the structure distortion of $\mathrm{M}_{1} / \mathrm{DV}-\mathrm{G}$, especially $\mathrm{Pd}_{1} / \mathrm{DV}$ $\mathrm{G}$ (Fig. S6). The downward $\mathrm{Pd}_{1}$ atom severely affects the further acetylene adsorption and the hydrogenation activity. The cleaved $\mathrm{H}$ atoms on $\mathrm{M}_{1} / \mathrm{DV}-\mathrm{G}$ are protic with positive Bader charges, suggesting that the carbon atoms nearby the central metal SA on DV-G may play an important role to bind the $\mathrm{H}$ atom via electron sharing. The origin for the different $\mathrm{H}_{2}$ adsorption behavior can be ascribed to the coordination number of metal SAs. In $D V-G$, four $M-C_{G}$ bonds are formed between the metal $\mathrm{SA}$ and the nearby $\mathrm{C}$ atoms with the Mayer bond order of $\sim 0.6$ (Ni: 0.63; Pd: 0.66; Pt: 0.66). While, the formed three $\mathrm{M}-\mathrm{C}_{\mathrm{G}}$ bonds in $\mathrm{M}_{1} / \mathrm{SV}-\mathrm{G}$ possess larger Mayer bond order, $0.84,0.93$ and 1.02 for $\mathrm{Ni}, \mathrm{Pd}$ and $\mathrm{Pt}$, respectively. As a result, the $\mathrm{C}$ atoms with lower saturation in DV-G become favorable landing sites for the dissociated $\mathrm{H}$ atoms. On the contrary, the cleaved $\mathrm{H}$ atoms prefer to bind with the three coordinated metal SAs in $\mathrm{M}_{1} / \mathrm{SV}$-G. As shown in Figs S7 and S8, the adsorbed $\mathrm{H}$ atom at the

Table 2 Adsorption energy $\left(E_{\mathrm{ads}}, \mathrm{eV}\right)$ of $\mathrm{H}_{2}$ on the single-atom site of $\mathrm{M}_{1} / \mathrm{SV}-\mathrm{G}$ and $\mathrm{M}_{1} / \mathrm{DV}-\mathrm{G}(\mathrm{M}=\mathrm{Ni}, \mathrm{Pd} \text { and } \mathrm{Pt})^{\mathrm{a}}$

\begin{tabular}{|c|c|c|c|c|c|c|}
\hline \multirow{2}{*}{ Mode } & \multicolumn{3}{|c|}{ SV-G } & \multicolumn{3}{|c|}{ DV-G } \\
\hline & $\mathrm{Ni}$ & $\mathrm{Pd}$ & $\mathrm{Pt}$ & $\mathrm{Ni}$ & $\mathrm{Pd}$ & $\mathrm{Pt}$ \\
\hline $\mathrm{H}_{2}$ & -0.15 & -0.18 & -0.29 & 0.03 & -0.08 & -0.02 \\
\hline HH-1 & 0.50 & 0.77 & -0.34 & - & - & 0.35 \\
\hline HH-2 & 0.08 & 0.27 & -0.05 & - & - & - \\
\hline HH-3 & 0.09 & 0.57 & 0.88 & $-1.47 /-1.00$ & $-2.11 /-0.85$ & $-0.87 /-0.26$ \\
\hline
\end{tabular}

a) On $\mathrm{M}_{1} / \mathrm{DV}$-G surface, $\mathrm{HH}-3$ has two different types, one case is with the two $\mathrm{H}$ atoms in ortho-positions, the other case with para-positions. 
SA site will diffuse to the nearby $\mathrm{C}$ site during the geometry optimization process on the $\mathrm{Pt}_{1} / \mathrm{DV}-\mathrm{G}$ surface. However, the transfer of $\mathrm{H}$ atom from the SA site to the nearby $\mathrm{C}$ atom on $\mathrm{Pt}_{1} / \mathrm{SV}-\mathrm{G}$ needs to overcome an energy barrier as large as $1.14 \mathrm{eV}$ (Fig. S9).

We also calculated the $\mathrm{H}_{2}$ dissociation process on each surface. For the $\mathrm{M}_{1} / \mathrm{SV}-\mathrm{G}$ cases (Fig. $2 \mathrm{a}$ ), $\mathrm{Pd}_{1}$ has the largest energy barrier, and $\mathrm{Pt}_{1}$ has the lowest energy barrier. The results are consistent with the BrønstedEvans-Polanyi (BEP) relationship, which indicates that the reaction barrier increases with the increase of reaction energy for each elementary step [68]. For the $M_{1} / D V-G$ cases (Fig. 2b), $\mathrm{Pd}_{1}$ still has the highest energy barrier. The dissociation energy barrier on $\mathrm{M}_{1} / \mathrm{DV}-\mathrm{G}$ is generally lower than that on $\mathrm{M}_{1} / \mathrm{SV}-\mathrm{G}$, except for $\mathrm{Pt}_{1}$, in which case the energy barrier on $\mathrm{Pt}_{1} / \mathrm{DV}-\mathrm{G}$ is $0.21 \mathrm{eV}$ higher than that on $\mathrm{Pt}_{1} / \mathrm{SV}-\mathrm{G}$. The results indicate that the $\mathrm{H}_{2}$ dissociation capability of $M_{1} / D V-G$ is superior to that of $\mathrm{M}_{1} / \mathrm{SV}-\mathrm{G}$ surface.

\section{Hydrogenation mechanism}

$\mathrm{C}_{2} \mathrm{H}_{2}$ hydrogenation on $\mathrm{M}_{1} / \mathrm{SV}-\mathrm{G}(\mathrm{M}=\mathrm{Ni}, \mathrm{Pd}$ and $\mathrm{Pt})$

According to our calculations, the adsorption of $\mathrm{C}_{2} \mathrm{H}_{2}$ on
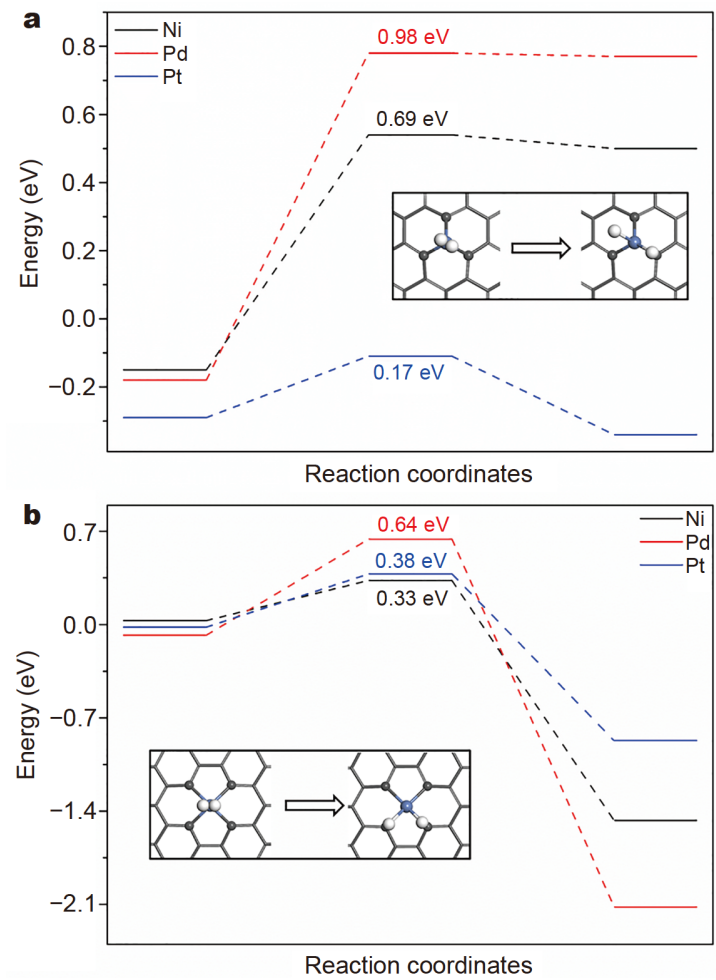

Figure 2 Energy profiles of $\mathrm{H}_{2}$ dissociation on (a) $\mathrm{M}_{1} / \mathrm{SV}-\mathrm{G}$, and (b) $\mathrm{M}_{1} / \mathrm{DV}-\mathrm{G}(\mathrm{M}=\mathrm{Ni}, \mathrm{Pd}$ and $\mathrm{Pt})$.
$\mathrm{M}_{1} / \mathrm{SV}-\mathrm{G}$ surface is much easier than $\mathrm{H}_{2}$. Therefore, the metal center of $\mathrm{M}_{1} / \mathrm{SV}-\mathrm{G}$ will be occupied by $\mathrm{C}_{2} \mathrm{H}_{2}$ first. The most stable co-adsorption configuration of $\mathrm{C}_{2} \mathrm{H}_{2}$ and $\mathrm{H}_{2}$ is with $\mathrm{H}_{2}$ dissociated (Fig. S10a), indicating that the hydrogenation process of $\mathrm{C}_{2} \mathrm{H}_{2}$ on $\mathrm{M}_{1} / \mathrm{SV}-\mathrm{G}$ proceeds through the Horiuti-Polanyi mechanism [69]. The energy profiles of $\mathrm{C}_{2} \mathrm{H}_{2}$ hydrogenation process on $\mathrm{M}_{1} / \mathrm{SV}-\mathrm{G}$ are presented in Fig. 3. The dissociation of $\mathrm{H}_{2}$ needs to overcome high energy barriers of 1.22, 2.11 and $1.14 \mathrm{eV}$, respectively, which are higher than the corresponding $\mathrm{H}_{2}$ dissociation barriers on clean $\mathrm{M}_{1} / \mathrm{SV}-\mathrm{G}$. As reported by Shang and Liu [70], the critical value for a surface reaction to take place at room temperature is around $0.75 \mathrm{eV}$, in this regard, the large barriers of $\mathrm{H}_{2}$ dissociation on $\mathrm{M}_{1}$ / SV-G surfaces will impede the hydrogenation reaction. We also found that the co-adsorption energy of $\mathrm{C}_{2} \mathrm{H}_{2}$ dimer (Fig. S10b), which is the competing process for hydrogenation of acetylene, is almost comparable to or even larger $\left(\mathrm{Pd}_{1} / \mathrm{SV}-\mathrm{G}\right.$ and $\mathrm{Pt}_{1} / \mathrm{SV}-\mathrm{G}$ surface $)$ than that of $\mathrm{C}_{2} \mathrm{H}_{2}$ and $\mathrm{H}_{2}$. This indicates that the co-adsorbed $\mathrm{C}_{2} \mathrm{H}_{2}$ dimer can cover the active sites, which would further

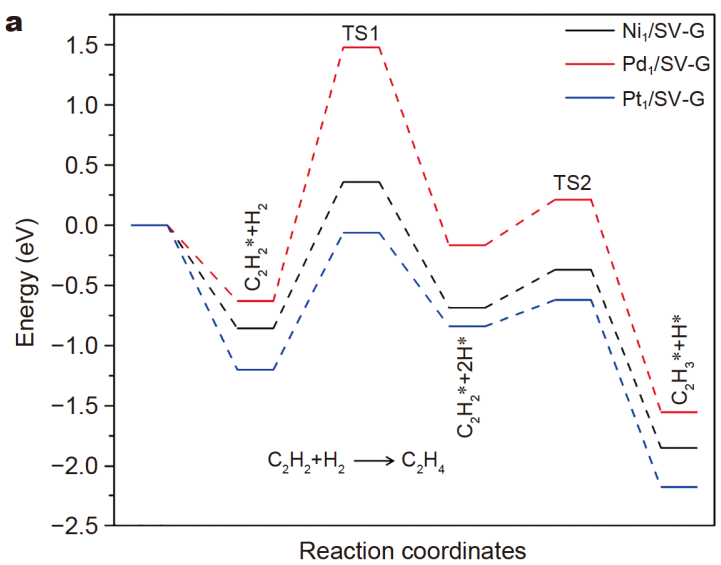

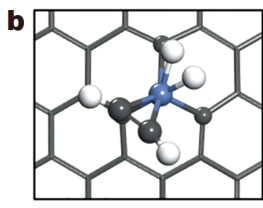

$\mathrm{Ni}$ /SV-G-TS1

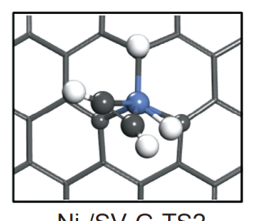

$\mathrm{Ni}$, /SV-G-TS2

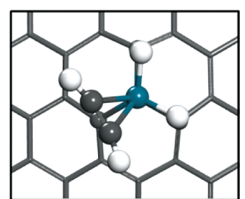

$\mathrm{Pd}$, /SV-G-TS1

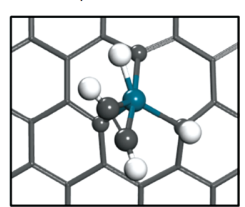

$\mathrm{Pd}_{1} / \mathrm{SV}-\mathrm{G}-\mathrm{TS} 2$

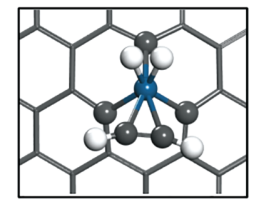

$\mathrm{Pt}$ /SV-G-TS1

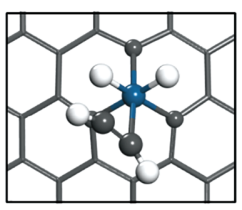

$\mathrm{Pt}_{1} / \mathrm{SV}-\mathrm{G}-\mathrm{TS} 2$
Figure 3 (a) Energy profiles of $\mathrm{C}_{2} \mathrm{H}_{2}$ hydrogenation and (b) corresponding structures of transition states on $\mathrm{M}_{1} / \mathrm{SV}-\mathrm{G}(\mathrm{M}=\mathrm{Ni}$, $\mathrm{Pd}$ and $\mathrm{Pt})$. 
hinder the dissociation of $\mathrm{H}_{2}$. Thus, the $\mathrm{M}_{1} / \mathrm{SV}-\mathrm{G}$ catalysts are hardly eligible for acetylene hydrogenation reactions due to high $\mathrm{H}_{2}$ dissociation barriers and large coadsorption energies of $\mathrm{C}_{2} \mathrm{H}_{2}$ dimer.

\section{$\mathrm{C}_{2} \mathrm{H}_{2}$ hydrogenation on $\mathrm{M}_{1} / D V-G(M=N i, P d$ and $\mathrm{Pt})$}

Different from the $\mathrm{M}_{1} / \mathrm{SV}-\mathrm{G}$ cases, $\mathrm{H}_{2}$ dissociation on $\mathrm{M}_{1} /$ DV-G is much easier, so the reaction starts with the adsorption of $\mathrm{HH}^{*}$. For the hydrogenation process on $\mathrm{Ni}_{1} /$ DV-G (Fig. 4, black line), $\mathrm{C}_{2} \mathrm{H}_{2}$ is first hydrogenated to $\mathrm{C}_{2} \mathrm{H}_{4}$ through an ethylene-like $\mathrm{C}_{2} \mathrm{H}_{3} \mathrm{Ni}$ intermediate by two steps. The hydrogenation barriers of the first and second steps are 0.89 and $0.60 \mathrm{eV}$, respectively. $\mathrm{On} \mathrm{Pd}_{1} /$ DV-G (Fig. 4, red line), the barrier of the first hydrogenation step is $1.54 \mathrm{eV}$ (TS1), and the second step is $0.82 \mathrm{eV}$ (TS2). On $\mathrm{Pt}_{1} / \mathrm{DV}-\mathrm{G}$ (Fig. 4, blue line), the energy barrier is $0.79 \mathrm{eV}$ (TS1) and $0.72 \mathrm{eV}$ (TS2), respectively. Thus, $\mathrm{Ni}_{1} / \mathrm{DV}-\mathrm{G}$ and $\mathrm{Pt}_{1} / \mathrm{DV}-\mathrm{G}$ present better catalytic activity than $\mathrm{Pd}_{1} / \mathrm{DV}-\mathrm{G}$, likely due to relativistic effects. Further hydrogenation of $\mathrm{C}_{2} \mathrm{H}_{4}$ on $\mathrm{Ni}_{1} / \mathrm{DV}-\mathrm{G}$ and $\mathrm{Pt}_{1} /$ DV-G (Fig. S11) needs to overcome barriers of 0.80 and $0.60 \mathrm{eV}$ to form the $\mathrm{C}_{2} \mathrm{H}_{5}$ * intermediate, which are 0.39 and $0.12 \mathrm{eV}$ higher than the desorption energies of $\mathrm{C}_{2} \mathrm{H}_{4}$ $\left(0.41\right.$ and $0.48 \mathrm{eV}$ ), implying that $\mathrm{C}_{2} \mathrm{H}_{4}$ prefers desorption

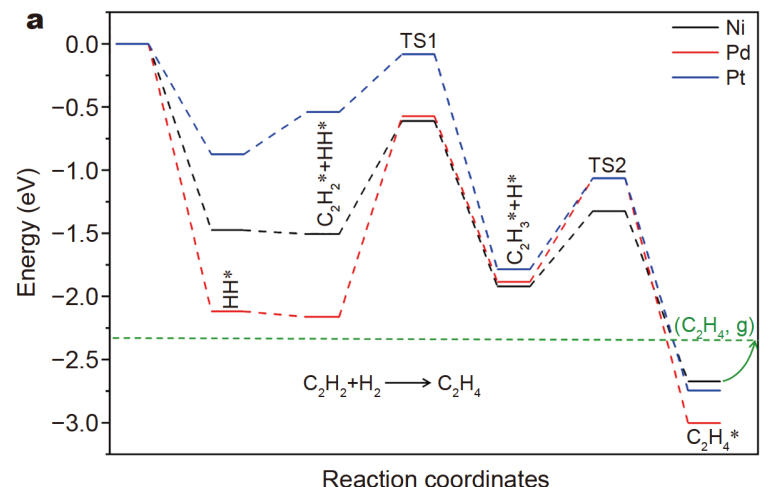

b

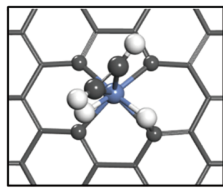

$\mathrm{Ni}, / D V-G-T S 1$

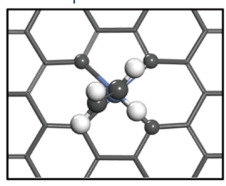

$\mathrm{Ni}_{1} / \mathrm{DV}-\mathrm{G}-\mathrm{TS} 2$

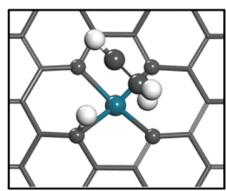

$\mathrm{Pd}_{1} / \mathrm{DV}-\mathrm{G}-\mathrm{TS} 1$

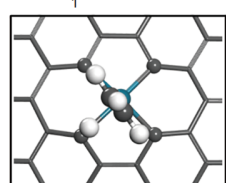

$\mathrm{Pd}_{1} / \mathrm{DV}-\mathrm{G}-\mathrm{TS} 2$

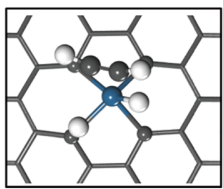

$\mathrm{Pt} / \mathrm{DV}-\mathrm{G}-\mathrm{TS} 1$

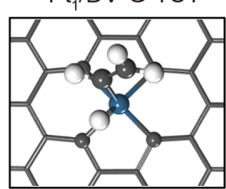

$\mathrm{Pt}_{1} / \mathrm{DV}-\mathrm{G}-\mathrm{TS} 2$

Figure 4 (a) Energy profiles of $\mathrm{C}_{2} \mathrm{H}_{2}$ hydrogenation and (b) corresponding structures of transition states on $\mathrm{M}_{1} / \mathrm{DV}-\mathrm{G}(\mathrm{M}=\mathrm{Ni}$, $\mathrm{Pd}$ and $\mathrm{Pt})$.

to further hydrogenation on both catalysts. As reported by previous work, the energy difference defined as $\Delta E_{\mathrm{sel}}=E_{\mathrm{a}}-E_{\mathrm{des}}$ can be used to estimate the reaction selectivity [61], where $E_{\mathrm{a}}$ and $E_{\text {des }}$ are the effective hydrogenation barrier of $\mathrm{C}_{2} \mathrm{H}_{4}+\mathrm{H}_{2} \rightarrow \mathrm{C}_{2} \mathrm{H}_{6}$ and the desorption energy of $\mathrm{C}_{2} \mathrm{H}_{4}$, respectively. Obviously, $\mathrm{Ni}_{1} / \mathrm{DV}-\mathrm{G}$ has larger $\Delta E_{\text {sel }}$ than $\mathrm{Pt}_{1} / \mathrm{DV}-\mathrm{G}$, implying better selectivity for the former.

In order to compare the activities of different metal elements for the hydrogenation of acetylene to ethylene, turnover frequencies (TOFs) were calculated according to the energetic span model [71-73],

$\mathrm{TOF} \approx \frac{k_{\mathrm{B}} T}{h} \mathrm{e}^{-E_{\mathrm{a}}} \mathrm{eff}_{R T}$,

where $E_{\mathrm{a}}^{\text {eff }}$ is the effective reaction barrier that is the energy difference between the two rate-determining states in the whole reaction instead of the reaction barrier of the rate determining step. The estimated $\ln (\mathrm{TOF})$ was plotted against the adsorption energies of acetylene on different catalysts (Fig. 5). Ni 1 /DV-G and $\mathrm{Pt}_{1} / \mathrm{DV}-\mathrm{G}$ show better hydrogenation activities than $\mathrm{Pd}_{1} / \mathrm{DV}-\mathrm{G}$, which is with the strongest acetylene adsorption energy. The results are totally different for the same metal SAs alloyed on the $\mathrm{Cu}$ (111) surface [74]. As reported by Yang et al. [74], $\mathrm{Pd}_{1}-\mathrm{Cu}$ and $\mathrm{Pt}_{1}-\mathrm{Cu}$ are more active hydrogenation catalysts than $\mathrm{Ni}_{1}-\mathrm{Cu}$. The reason may be attributed to the inert DV-G support, which changes the electronic structures of embedded metal SAs, the acetylene adsorption mode and the $\mathrm{H}_{2}$ dissociation pathway (see insert of Fig. 5). On the $\mathrm{M}_{1} /$ DV-G surface, the $\pi$ adsorption mode of acetylene and ethylene inhibits the side reactions, whilst benefits the desorption of ethylene, a key for semi-hydrogenation of acetylene. In addition, the less saturated $\mathrm{C}$ atoms nearby

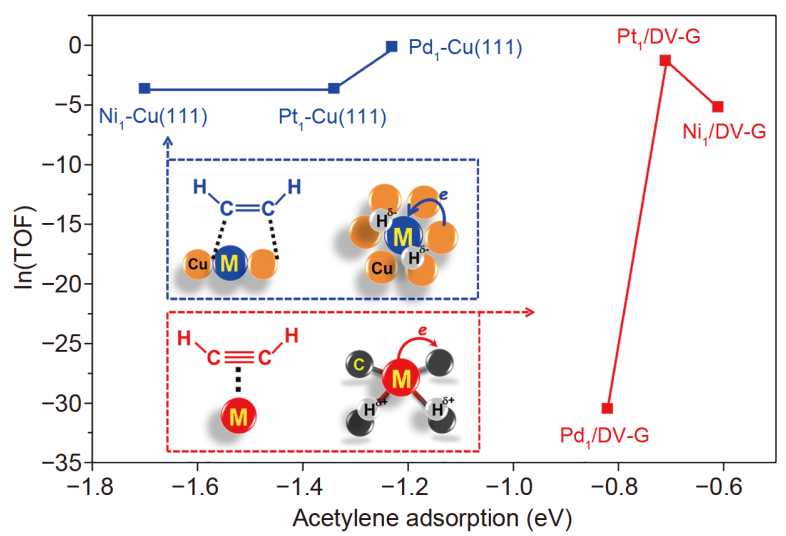

Figure 5 Plots of $\ln (\mathrm{TOF})$ against the adsorption energy of acetylene, with data of blue points from Ref [74]. 
the central metal SA play a key role in the dissociation of $\mathrm{H}_{2}$, and the dissociated $\mathrm{H}$ atoms are active for the further hydrogenation reaction.

\section{CONCLUSIONS}

In summary, we have expounded the reaction pathways of acetylene hydrogenation on DG-supported SACs through computational chemistry study. We have found that one of the keys for the hydrogenation reaction on $M_{1} / D G$ is the dissociation of $H_{2}$. The DV-G support provides higher hydrogenation activity than the SV-G support, and the activity follows the order of $\mathrm{Pt}>\mathrm{Ni}>>$ $\mathrm{Pd}$, which can be explained by the large relativistic effects for Pt. On $\mathrm{M}_{1} / \mathrm{SV}-\mathrm{G}$, the dissociation of $\mathrm{H}_{2}$ directly affects the hydrogenation activity, and the huge structure distortion of $\mathrm{HH}-3$ dissociative adsorption on $\mathrm{Pd}_{1} / \mathrm{DV}-\mathrm{G}$ impedes the hydrogenation reaction. Furthermore, we propose the $\mathrm{Ni}_{1} / \mathrm{DV}-\mathrm{G}$ as a highly active and selective catalyst for selective hydrogenation of acetylene, which enriches the wide applications of graphene-supported SACs [75]. Our results provide important theoretical insights into the active site of $\mathrm{M}_{1}$ /graphene catalysts and the further design of noble-metal-free catalysts for selective hydrogenation of acetylene.

\section{Received 15 May 2020; accepted 8 June 2020;} published online 17 July 2020

1 Borodziński A, Bond GC. Selective hydrogenation of ethyne in ethene-rich streams on palladium catalysts. Part 1. Effect of changes to the catalyst during reaction. Catal Rev, 2006, 48: 91-144

2 Borodziński A, Bond GC. Selective hydrogenation of ethyne in ethane-rich streams on palladium catalysts. Part 2: Steady-state kinetics and effects of palladium particle size, carbon monoxide, and promoters. Catal Rev, 2008, 50: 379-469

3 Vilé G, Albani D, Almora-Barrios N, et al. Advances in the design of nanostructured catalysts for selective hydrogenation. ChemCatChem, 2016, 8: 21-33

4 Mueller WM, Blackledge JP, Libowitz GG. Metal Hydrides. New York, London: Academic Press, 1968

5 Armbrüster M, Behrens M, Cinquini F, et al. How to control the selectivity of palladium-based catalysts in hydrogenation reactions: The role of subsurface chemistry. ChemCatChem, 2012, 4: 10481063

6 Teschner D, Borsodi J, Wootsch A, et al. The roles of subsurface carbon and hydrogen in palladium-catalyzed alkyne hydrogenation. Science, 2008, 320: 86-89

7 Studt F, Abild-Pedersen F, Bligaard T, et al. On the role of surface modifications of palladium catalysts in the selective hydrogenation of acetylene. Angew Chem Int Ed, 2008, 47: 9299-9302

8 Yang B, Burch R, Hardacre C, et al. Influence of surface structures, subsurface carbon and hydrogen, and surface alloying on the activity and selectivity of acetylene hydrogenation on Pd surfaces: A density functional theory study. J Catal, 2013, 305: 264-276

9 Michaelides A, Hu P, Alavi A. Physical origin of the high reactivity of subsurface hydrogen in catalytic hydrogenation. J Chem Phys, 1999, 111: 1343-1345

10 Ledentu V, Dong W, Sautet P. Heterogeneous catalysis through subsurface sites. J Am Chem Soc, 2000, 122: 1796-1801

11 Haug KL, Bürgi T, Trautman TR, et al. Distinctive reactivities of surface-bound $\mathrm{H}$ and bulk $\mathrm{H}$ for the catalytic hydrogenation of acetylene. J Am Chem Soc, 1998, 120: 8885-8886

12 Tew MW, Miller JT, van Bokhoven JA. Particle size effect of hydride formation and surface hydrogen adsorption of nanosized palladium catalysts: $\mathrm{L}_{3}$ edge $v$. $\mathrm{K}$ edge X-ray absorption spectroscopy. J Phys Chem C, 2009, 113: 15140-15147

13 Sárkány A, Weiss AH, Guczi L. Structure sensitivity of acetyleneethylene hydrogenation over Pd catalysts. J Catal, 1986, 98: 550553

14 Aben P. Palladium areas in supported catalysts: Determination of palladium surface areas in supported catalysts by means of hydrogen chemisorption. J Catal, 1968, 10: 224-229

15 Qiao B, Wang A, Yang X, et al. Single-atom catalysis of CO oxidation using $\mathrm{Pt}_{1} / \mathrm{FeO}_{x}$. Nat Chem, 2011, 3: 634-641

16 Yang XF, Wang A, Qiao B, et al. Single-atom catalysts: A new frontier in heterogeneous catalysis. Acc Chem Res, 2013, 46: 17401748

17 Liang S, Hao C, Shi Y. The power of single-atom catalysis. ChemCatChem, 2015, 7: 2559-2567

18 Liu J. Catalysis by supported single metal atoms. ACS Catal, 2017, 7: 34-59

19 Liang JX, Wang YG, Yang XF, et al. Recent advances in singleatom catalysis. Encyclop Inorga Bioinorg Chem, 2017, 1-11

20 Liu JC, Tang Y, Wang YG, et al. Theoretical understanding of the stability of single-atom catalysts. Natl Sci Rev, 2018, 5: 638-641

21 Wang A, Li J, Zhang T. Heterogeneous single-atom catalysis. Nat Rev Chem, 2018, 2: 65-81

22 Talib SH, Yu X, Yu Q, et al. Non-noble metal single-atom catalysts with phosphotungstic acid (PTA) support: A theoretical study of ethylene epoxidation. Sci China Mater, 2020, 63: 1003-1014

23 Harrath $\mathrm{K}, \mathrm{Yu} \mathrm{X}$, Xiao $\mathrm{H}$, et al. The key role of support surface hydrogenation in the $\mathrm{CH}_{4}$ to $\mathrm{CH}_{3} \mathrm{OH}$ selective oxidation by a $\mathrm{ZrO}_{2}$-supported single-atom catalyst. ACS Catal, 2019, 9: 89038909

24 Baskaran S, Xu CQ, Wang YG, et al. Catalytic mechanism and bonding analyses of Au-Pd single atom alloy (SAA): $\mathrm{CO}$ oxidation reaction. Sci China Mater, 2020, 63: 993-1002

25 Kyriakou G, Boucher MB, Jewell AD, et al. Isolated metal atom geometries as a strategy for selective heterogeneous hydrogenations. Science, 2012, 335: 1209-1212

26 Pei GX, Liu XY, Wang A, et al. Promotional effect of Pd single atoms on $\mathrm{Au}$ nanoparticles supported on silica for the selective hydrogenation of acetylene in excess ethylene. New J Chem, 2014, 38: 2043-2051

27 Pei GX, Liu XY, Wang A, et al. Ag alloyed Pd single-atom catalysts for efficient selective hydrogenation of acetylene to ethylene in excess ethylene. ACS Catal, 2015, 5: 3717-3725

28 Liu D. DFT study of selective hydrogenation of acetylene to ethylene on Pd doping Ag nanoclusters. Appl Surf Sci, 2016, 386: 125-137

29 Sheth PA, Neurock M, Smith CM. First-principles analysis of the effects of alloying Pd with $\mathrm{Ag}$ for the catalytic hydrogenation of acetylene-ethylene mixtures. J Phys Chem B, 2005, 109: 1244912466

30 Zhou H, Yang X, Li L, et al. PdZn intermetallic nanostructure with 
Pd-Zn-Pd ensembles for highly active and chemoselective semihydrogenation of acetylene. ACS Catal, 2016, 6: 1054-1061

31 Feng $\mathrm{Q}$, Zhao S, Wang $\mathrm{Y}$, et al. Isolated single-atom Pd sites in intermetallic nanostructures: High catalytic selectivity for semihydrogenation of alkynes. J Am Chem Soc, 2017, 139: 7294-7301

32 Vilé G, Albani D, Nachtegaal M, et al. A stable single-site palladium catalyst for hydrogenations. Angew Chem Int Ed, 2015, 54: $11265-11269$

33 Huang X, Xia Y, Cao Y, et al. Enhancing both selectivity and coking-resistance of a single-atom $\mathrm{Pd}_{1} / \mathrm{C}_{3} \mathrm{~N}_{4}$ catalyst for acetylene hydrogenation. Nano Res, 2017, 10: 1302-1312

34 Wilde M, Fukutani K, Ludwig W, et al. Influence of carbon deposition on the hydrogen distribution in Pd nanoparticles and their reactivity in olefin hydrogenation. Angew Chem Int Ed, 2008, 47: 9289-9293

35 Tew MW, Janousch M, Huthwelker T, et al. The roles of carbide and hydride in oxide-supported palladium nanoparticles for alkyne hydrogenation. J Catal, 2011, 283: 45-54

36 Teschner D, Vass E, Havecker M, et al. Alkyne hydrogenation over Pd catalysts: A new paradigm. J Catal, 2006, 242: 26-37

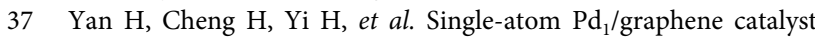
achieved by atomic layer deposition: Remarkable performance in selective hydrogenation of 1,3-butadiene. J Am Chem Soc, 2015, 137: 10484-10487

38 Huang F, Deng Y, Chen Y, et al. Atomically dispersed Pd on nanodiamond/graphene hybrid for selective hydrogenation of acetylene. J Am Chem Soc, 2018, 140: 13142-13146

39 Kresse G, Furthmüller J. Efficient iterative schemes for $a b$ initio total-energy calculations using a plane-wave basis set. Phys Rev B, 1996, 54: 11169-11186

40 Kresse G, Furthmüller J. Efficiency of ab-initio total energy calculations for metals and semiconductors using a plane-wave basis set. Comput Mater Sci, 1996, 6: 15-50

41 Perdew JP, Burke K, Ernzerhof M. Generalized gradient approximation made simple. Phys Rev Lett, 1996, 77: 3865-3868

42 Bader RFW. A quantum theory of molecular structure and its applications. Chem Rev, 1991, 91: 893-928

43 Jónsson H, Mills G, Jacobsen KW. Nudged elastic band method for finding minimum energy paths of transitions. In: Berne BJ, Ciccotti G, Coker DF (EDs.). Classical and Quantum Dynamics in Condensed Phase Simulations. Singapore, New Jersey, London, Hong Kong: World Scientific, 1998. 385-404

44 Henkelman G, Uberuaga BP, Jónsson H. A climbing image nudged elastic band method for finding saddle points and minimum energy paths. J Chem Phys, 2000, 113: 9901-9904

45 Henkelman G, Jónsson H. Improved tangent estimate in the nudged elastic band method for finding minimum energy paths and saddle points. J Chem Phys, 2000, 113: 9978-9985

46 Sargolzaei M, Gudarzi F. Magnetic properties of single 3d transition metals adsorbed on graphene and benzene: A density functional theory study. J Appl Phys, 2011, 110: 064303

47 Krasheninnikov AV, Lehtinen PO, Foster AS, et al. Embedding transition-metal atoms in graphene: Structure, bonding, and magnetism. Phys Rev Lett, 2009, 102: 126807

48 Santos EJG, Ayuela A, Sánchez-Portal D. First-principles study of substitutional metal impurities in graphene: Structural, electronic and magnetic properties. New J Phys, 2010, 12: 053012

49 Tang Y, Yang Z, Dai X. Trapping of metal atoms in the defects on graphene. J Chem Phys, 2011, 135: 224704

50 Xie PY, Zhang GL, Lv YA, et al. Enhanced bonding between noble metal adatoms and graphene with point defects. Acta Phys-Chim Sin, 2012, 28: 331-337

51 Ning Z, Chen Z, Du X, et al. Structural stability, electronic and magnetic properties of $\mathrm{Cu}$ adsorption on defected graphene: A first principles study. J Supercond Nov Magn, 2013, 27: 115-120

52 Wang L, Luo Q, Zhang W, et al. Transition metal atom embedded graphene for capturing CO: A first-principles study. Int J Hydrogen Energy, 2014, 39: 20190-20196

53 Yan H, Zhao X, Guo N, et al. Atomic engineering of high-density isolated Co atoms on graphene with proximal-atom controlled reaction selectivity. Nat Commun, 2018, 9: 3197

54 Jia TT, Lu CH, Zhang YF, et al. A comparative study of CO catalytic oxidation on Pd-anchored graphene oxide and Pd-embedded vacancy graphene. J Nanopart Res, 2014, 16: 2206

55 Liu X, Sui Y, Duan T, et al. CO oxidation catalyzed by Ptembedded graphene: A first-principles investigation. Phys Chem Chem Phys, 2014, 16: 23584-23593

56 Johll H, Kang HC, Tok ES. Density functional theory study of Fe, $\mathrm{Co}$, and $\mathrm{Ni}$ adatoms and dimers adsorbed on graphene. Phys Rev B, 2009, 79: 245416

57 Back S, Lim J, Kim NY, et al. Single-atom catalysts for $\mathrm{CO}_{2}$ electroreduction with significant activity and selectivity improvements. Chem Sci, 2017, 8: 1090-1096

$58 \mathrm{Xu} \mathrm{H}$, Cheng D, Cao D, et al. A universal principle for a rational design of single-atom electrocatalysts. Nat Catal, 2018, 1: 339-348

59 Li XF, Li QK, Cheng J, et al. Conversion of dinitrogen to ammonia by $\mathrm{FeN}_{3}$-embedded graphene. J Am Chem Soc, 2016, 138: 87068709

60 Xi Y, Heyden A. Direct oxidation of methane to methanol enabled by electronic atomic monolayer-metal support interaction. ACS Catal, 2019, 9: 6073-6079

61 Yang B, Burch R, Hardacre C, et al. Origin of the increase of activity and selectivity of nickel doped by $\mathrm{Au}, \mathrm{Ag}$, and $\mathrm{Cu}$ for acetylene hydrogenation. ACS Catal, 2012, 2: 1027-1032

62 Medlin JW, Allendorf MD. Theoretical study of the adsorption of acetylene on the (111) surfaces of Pd, Pt, Ni, and Rh. J Phys Chem B, 2003, 107: 217-223

63 Zhang L, Ren Y, Liu W, et al. Single-atom catalyst: A rising star for green synthesis of fine chemicals. Natl Sci Rev, 2018, 5: 653-672

64 Xu CQ, Xing DH, Xiao H, et al. Manipulating stabilities and catalytic properties of trinuclear metal clusters through tuning the chemical bonding: $\mathrm{H}_{2}$ adsorption and activation. J Phys Chem C, 2017, 121: 10992-11001

65 Watson GW, Wells RPK, Willock DJ, et al. A comparison of the adsorption and diffusion of hydrogen on the $\{111\}$ surfaces of $\mathrm{Ni}$, $\mathrm{Pd}$, and Pt from density functional theory calculations. J Phys Chem B, 2001, 105: 4889-4894

66 Tolbert MA, Beauchamp JL. Homolytic and heterolytic bond dissociation energies of the second row group 8, 9, and 10 diatomic transition-metal hydrides: Correlation with electronic structure. J Phys Chem, 1986, 90: 5015-5022

67 Pearson RG. The transition-metal-hydrogen bond. Chem Rev, 1985, 85: 41-49

68 Evans MG, Polanyi M. Inertia and driving force of chemical reactions. Trans Faraday Soc, 1938, 34: 11-24

69 Horiuti I, Polanyi M. Exchange reactions of hydrogen on metallic catalysts. Trans Faraday Soc, 1934, 30: 1164-1172

70 Shang C, Liu ZP. Origin and activity of gold nanoparticles as aerobic oxidation catalysts in aqueous solution. J Am Chem Soc, 2011, 133: 9938-9947 
71 Kozuch S, Shaik S. How to conceptualize catalytic cycles? The energetic span model. Acc Chem Res, 2010, 44: 101-110

72 Kozuch S, Shaik S. A combined kinetic-quantum mechanical model for assessment of catalytic cycles: Application to crosscoupling and heck reactions. J Am Chem Soc, 2006, 128: 33553365

73 Kozuch S. Steady state kinetics of any catalytic network: Graph theory, the energy span model, the analogy between catalysis and electrical circuits, and the meaning of "mechanism". ACS Catal, 2015, 5: 5242-5255

74 Yang K, Yang B. Surface restructuring of Cu-based single-atom alloy catalysts under reaction conditions: The essential role of adsorbates. Phys Chem Chem Phys, 2017, 19: 18010-18017

75 Ren S, Yu Q, Yu X, et al. Graphene-supported metal single-atom catalysts: A concise review. Sci China Mater, 2020, 63: 903-920

Acknowledgements This work was supported by the National Natural Science Foundation of China (21573286, 21173269, 21576288, U1662104, 21590792 and 91645203), the Ministry of Science and Technology of China (2015AA034603), the Specialized Research Fund for the Doctoral Program of Higher Education (20130007110003), the Science Foundation of China University of Petroleum, Beijing (2462015YQ0304), and Guangdong Provincial Key Laboratory of Catalysis (2020B121201002). The calculations were performed using supercomputers at SUSTech Supercomputer Center and Tsinghua National Laboratory for Information Science and Technology.

Author contributions Li J conceived the project; Zhuo HY and Yu X performed the calculations; Zhuo HY and Xiao $\mathrm{H}$ wrote the paper; Yu $\mathrm{XH}, \mathrm{Yu} \mathrm{Q}$, Xiao H, Zhang X and Li J revised the manuscript. All authors discussed the results and commented on the manuscript.

Conflict of interest The authors declare that they have no conflict of interest.

Supplementary information online version of the paper.

Supporting data are available in the

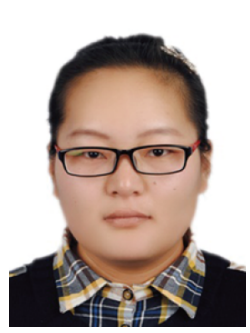

Hong-Ying Zhuo is currently a $\mathrm{PhD}$ candidate in Prof. Xin Zhang's group at China University of Petroleum-Beijing. She got her BSc degree in applied chemistry from Yantai University in 2011, and MSc degree in physical chemistry in 2015. Now, she is also a visiting student in Prof. Jun Li's group, Tsinghua University (Beijing, China). Her current research interests focus on heterogeneous catalysis through theoretical methods.

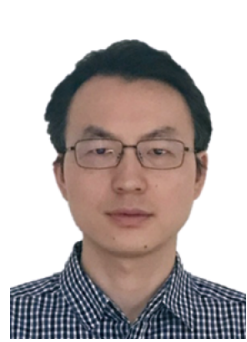

Hai Xiao received his $\mathrm{PhD}$ degree from California Institute of Technology (Caltech) in 2015. $\mathrm{He}$ then continued to work at Caltech as a postdoctoral scholar and later a research scientist from 2015 to 2018 . He is now an associate professor at Tsinghua University, and his research interest focuses on the fields of computational chemistry, catalysis and materials science.

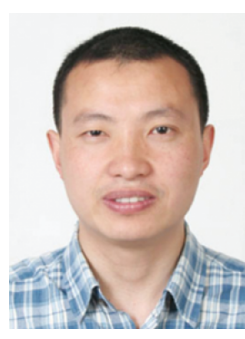

Xin Zhang has received his $\mathrm{PhD}$ degree in 2006 from Tsinghua University. During 2007-2008, he joined Prof. Avelino Corma Canos' group at the Instituto de Tecnología Química, Universidad Politécnica de Valencia in Spain (UPV-ITQ) as a postdoctoral fellow. In 2009, he started to work as a professor in the College of Chemical Engineering, China University of Petroleum, Beijing, China. His research focuses on the synthesis, characterization, and catalytic performance of catalysts with novel-structures.

\section{石墨烯负载的非贵金属单原子催化剂的乙炔选择} 性加氢反应研究

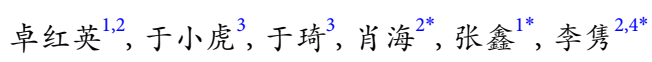

摘要 在工业上批量生产聚乙烯的过程中去除痕量乙炔杂质的常 用方法是沸石吸附或钯基催化剂选择性半氢化乙炔生成乙烯. 本 文通过密度泛函理论研究了乙炔在缺陷石墨烯负载的单原子催化 剂 $M_{1} / S V-G$ 和 $M_{1} / D V-G$ (其中 $M=N i, P d, P t ; S V-G, D V-G$ 分别代表 具有单碳缺陷和双碳缺陷的石墨烯)表面上加氢转化为乙烯的反应 机理. 研究表明, 金属单原子及其配位环境均会影响加氢过程的活 性和选择性. $M_{1} / D V-G$ 催化剂比 $M_{1} / S V-G$ 具有更好的氢分子解离 能力, 这是因为 $M_{1} / D V-G$ 具有较强的乙炔氢化能力. 基于计算得到 的加氢能垒, $\mathrm{Pt}_{1} / \mathrm{DV}-\mathrm{G}$ 和 $\mathrm{Ni}_{1} / \mathrm{DV}-\mathrm{G}$ 的催化活性明显优于其他催化 剂, 其中 $\mathrm{Ni}_{1} / \mathrm{DV}-\mathrm{G}$ 催化剂还具有高的乙炔半加氢选择性. 本研究结 果为设计以碳材料为载体的、具有高选择性的非贵金属单原子乙 炔氢化催化剂提供了理论基础. 